\title{
ANALYSIS OF WEIBULL PARAMETERS FOR WIND POWER GENERATION
}

\author{
O. D. Q. de Oliveira Filho ${ }^{a}$, \\ A. M. Araújo ${ }^{a}$, \\ W. F. A. Borges ${ }^{a}$, \\ A. A. C. Silva ${ }^{a}$, \\ C. C. A. Bezerra ${ }^{a}$, \\ E. C. R. Fernandes ${ }^{a}$, \\ E. J. F. Rocha ${ }^{a}$, \\ G. J. A. M. Rocha ${ }^{a}$, \\ L. I. Andrade ${ }^{a}$, \\ and D. G. Ribeiro ${ }^{b}$ \\ ${ }^{\mathrm{a}}$ Universidade Federal de Pernambuco \\ Departamento de Engenharia Mecânica \\ Programa de Pós-Graduação em Engenharia \\ Mecânica - PPGEM/UFPE \\ Avenida Prof. Moraes Rêgo, 1235 \\ Bairro Cidade Universitária \\ CEP 50670-901, Recife, Pernambuco, Brasil \\ oyamadouglas@gmail.com \\ ${ }^{\text {b} U n i v e r s i d a d e ~ d e ~ S a ̃ o ~ P a u l o ~}$ \\ Departamento de Engenharia Mecânica \\ Programa de Pós-Graduação em Engenharia \\ Mecânica - PPGEM/EESC-USP \\ Av. Trabalhador São-Carlense, 400 \\ CEP 13566-590, São Carlos, São Paulo, Brasil \\ Received: April 11, 2018 \\ Revised: May 11, 2018 \\ Accepted: May 23, 2018
}

\section{ABSTRACT}

The aim of the present work is to perform an analysis of both Weibull parameters $k$ and $c$ for wind power generation so that one can have an idea of how the mechanisms of wind energy estimation work and build a better understanding of these parameters. This paper covers aspects from the definition of continuous random variable to the analysis of the scale $(c)$ and shape $(k)$ parameters themselves. Mathematical and physical analysis will be performed and finally, a comparison between the parameters and their influence on wind analysis will be presented.

\section{NOMENCLATURE}

a lower limit of integration, Eq. (2)

b upper limit of integration, Eq. (2)

c scale parameter, $\mathrm{m} / \mathrm{s}$

CDF cumulative density function, Eq. (4)

$k \quad$ shape parameter, dimensionless

$\mathrm{P}$ ( ) probability function, Eq. (6)

PDF probability density function, Eq. (5)

$V \quad$ velocity, $\mathrm{m} / \mathrm{s}$

$V_{m} \quad$ mean wind speed, $\mathrm{m} / \mathrm{s}$

$\sigma_{\mathrm{V}} / \mathrm{V}_{\mathrm{m}}$ average turbulence intensity, dimensionless

$X \quad$ continuous random variable, Eq. (1)

$\infty \quad$ infinite, dimensionless

\section{Greek symbols}

Keywords: Weibull, wind energy, PDF, wind regime

$$
\begin{array}{ll}
\Gamma & \text { gamma function, Eq. (9) } \\
\sigma_{V} & \text { standard deviation of wind speed data, } \mathrm{m} / \mathrm{s}
\end{array}
$$

\section{INTRODUCTION}

Waloddi Weibull, a Swedish engineer settled in US, developed his probabilistic distribution in 1937. However, the first article on the subject was only published in 1939 and legitimized in 1951. Weibull presented a method that could be applied to a wide variety of problems, from the analysis of the resistance of steel to the stature of the inhabitants of the British Islands (Weibull, 1951; Silva, 2003). At first, some researchers rejected his theory, since that Weibull's statement establishes that the input data could select the distribution and the best fit of the 
parameters, which seemed something beyond reality (Silva, 2003).

Some researchers as Shainin Dorian and Leonard Johnson (apud Silva, 2003) applied and perfected the method, attesting to Weibull's claims. The US Air Force recognized the merit of the method and funded its research until 1975. Today, this method is most commonly used for reliability analysis, mainly mechanical failures. Nevertheless, it is also used for wind energy production prediction, as shown later in this paper (Silva, 2003; Usta, 2016; Arslan et al., 2014).

\section{CONTINUOUS RANDOM VARIABLE}

A continuous random variable is a variable that can take any value in an interval. It may be defined in a continuous interval or the whole real axis. Whatever the case, it is not possible to determine a non-zero probability to a specific value since there are infinite values and the sum of all the non-zero probabilities would be more than one. It is possible, however, to determine the probability of a continuous random variable to lie within a certain interval (Morettin and Bussab, 2002; Devore, 2006).

Being $X$ a continuous random variable, there is a non-negative function named $f(x)$, the probability density function (PDF) of $X$ such that (Fig. 1), for $f(x)$ $\geq 0$ :

$$
\begin{gathered}
\int_{-\infty}^{\infty} f(x) d x=1 \\
P(a<X<b)=\int_{a}^{b} f(x) d x
\end{gathered}
$$

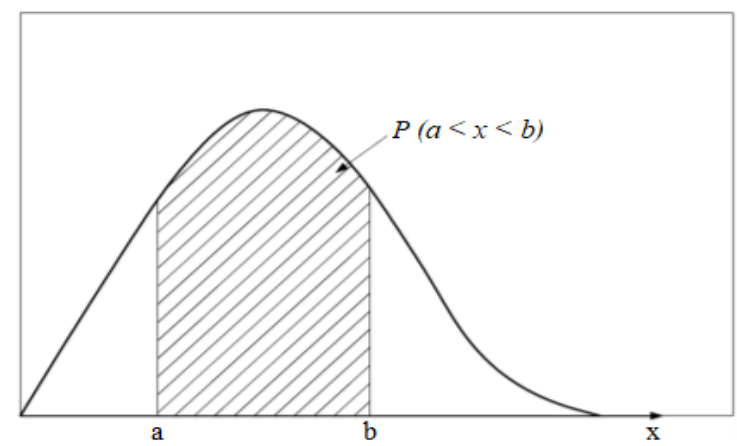

Figure 1. Graphic representation of the PDF.

For the same $X$, one can also define a cumulative distribution function (CDF) such that (Fig. 2):

$$
F(x)=P(X \leq x)=\int_{-\infty}^{x} f(u) d u
$$

The CDF is always increasing and,

$$
\lim _{x \rightarrow-\infty} F(x)=0 \text { and } \lim _{x \rightarrow \infty} F(x)=1
$$

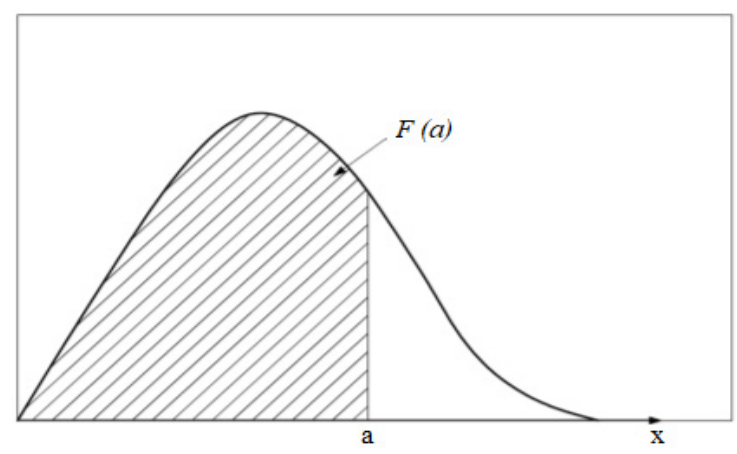

Figure 2. Graphic representation of the CDF.

\section{THE WEIBULL DISTRIBUTION}

There are a few probability distributions in literature that can be used to represent the wind behavior and its selection depends primarily on the characteristics of the observed wind regime (Silva, 2003; Usta, 2016; Jung and Schindler, 2017). The main distributions are:

- Normal or Gaussian distribution;

- Bivariate normal distribution;

- Exponential distribution;

- Rayleigh distribution; and

- Weibull distribution.

Actually, researchers wanted to obtain only one distribution that could best fit the wind behavior. The first studies of this kind were performed by (Silva 2003; Davenport, 1963; Hennessey, 1977; Justus et al., 1976). They showed that Weibull was the distribution that best represented the wind behavior, since it incorporates both the exponential distribution $(k=1)$ and the Rayleigh distribution $(k=2)$, also providing a good approximation of the normal distribution when the value of $k$ is greater than or equal to three (Silva, 2003).

The main parameters that support the use of the Weibull distribution for wind energy are:

- It is centered in a mean value and allows description of asymmetric behavior around this value;

- Depends on two parameters, $k$ and $c$;

- Incorporates particular cases (Rayleigh, for example);

- It is suitable to analyze extreme winds (Rohatgi et al., 2012).

The cumulative Weibull distribution gives the probability of the wind velocity to be less than or equal to a certain velocity $V$ and is written as follow (Lysen, 1983): 


$$
F(V)=1-\exp \left[-\left(\frac{V}{c}\right)^{k}\right]
$$

The PDF represents the fraction of time that the wind speed is centered in an interval of $1 \mathrm{~m} / \mathrm{s}$ in $V$ (Manwell et al., 2009), and is written as $f(V)=d F(V) / d V$, resulting in:

$$
f(V)=k \frac{V^{k-1}}{c^{k}} \exp \left[-\left(\frac{V}{c}\right)^{k}\right]
$$

where $k>0, V>0$ and $c>1$ (Johnson, 2001).

However, when integrating $f(V)=d F(V) / d V$ in a defined interval of wind speed, one can obtain the probability of the speeds of the interval:

$$
P\left(V_{i}<V<V_{i+1}\right)=\int_{V_{i}}^{V_{i+1}} f(V) d V=F\left(V_{i+1}\right)-F\left(V_{i}\right)
$$

where $\mathrm{i}=1,2,3, \ldots, \mathrm{n}$ (Johnson, 2001; Manwell et al., 2009).

The PDF gives the fraction of time at intervals centered in $1 \mathrm{~m} / \mathrm{s}$. One way to know the fraction of time of a velocity is to estimate $f(V)$ by Eq. (5) (Johnson, 2001). For example, the Weibull parameters at a given site are $c=6 \mathrm{~m} / \mathrm{s}$ and $k=2$. Estimate the number of hours per year that the wind speed will be between 6.5 and $7.5 \mathrm{~m} / \mathrm{s}$. By Eq. (5):

$$
f(7)=2 \frac{7^{2-1}}{6^{2}} \exp \left[-\left(\frac{7}{6}\right)^{2}\right]=0.0997[\mathrm{~s} / \mathrm{m}]
$$

or $9.97 \%$ of the time. The number of hours per year with the wind speed $V$ in this interval would be $(0.0997 \times 8760)=873$ hours/year.

The peak of the probability density curve (Fig. 3 ) indicates the most frequent wind velocity in the regime (Mathew, 2006). For any other interval, one must use the probability given by Eq. (6). For example, the Weibull parameters at a given site are $c$ $=6 \mathrm{~m} / \mathrm{s}$ and $k=2$. Estimate the number of hours per year that the wind speed will be between 6.5 and 7.0 m/s. By Eq. (6):

$$
\begin{aligned}
& P(6.5<V<7.0)=F(7.0)-F(6.5) \\
& =\exp \left[-\left(\frac{6.5}{6}\right)^{2}\right]-\exp \left[-\left(\frac{7.0}{6}\right)^{2}\right] \\
& =0.3092-0.2564 \\
& =0.0529
\end{aligned}
$$

The number of hours per year with wind speeds in this interval would be $(0.0529 \times 8760)=463$ hours/year.

It is noted from Eq. (6) that integrands are equally spaced from the center value $V$. This originates from the use of the Newton-Cotes Quadrature Rules for solving the integral, since the equations of Newton-Cotes are useful for numerical integration when the value of the integrand at equally spaced points is given. In addition, the interval is given in \pm 0.5 so that one can use the rectangular method of the Newton-Cotes equations, which has lower computational cost and a small error (Press, 2007).

\section{WEIBULL PARAMETERS - ANALYSIS AND DISCUSSION}

Analyzing Weibull parameters $k$ and $c$ from the PDF, fixing $c=2$, an increase in the value of $k$ causes wind velocity to concentrate around its mean value, as shown in Fig. 3.

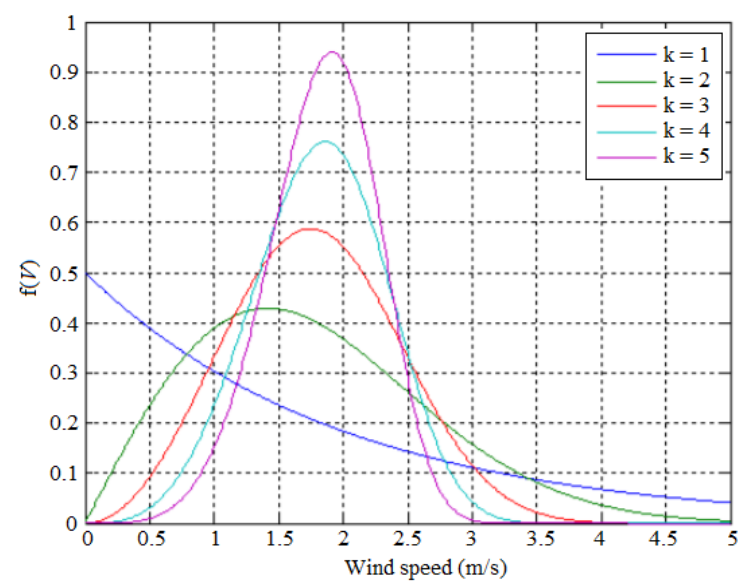

Figure 3. PDF for $c=2$ and $k$ varying from 1 to 5 .

For $k=1$, Weibull distribution incorporates the exponential function as previously said, which means that $\Gamma(2)=(2-1) !=1$, thus $c=V m$, as shown later.

Fixing $k=2$, an increase in the value of the scale parameter $c$ causes wind velocity to disperse around its main value as shown in Fig. 4.

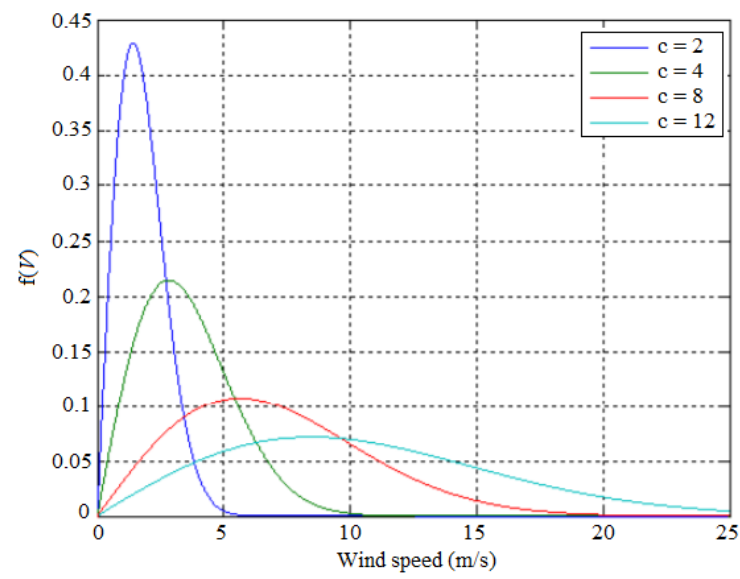

Figure 4. PDF for $k=2$ varying $c$. 
The PDF curves presented at Figs. 3 and 4 are adjusted according to $k$ and $c$. It is observed that the higher value of $k$, more constant the wind will be and the opposite happens for the parameter $c$. The characteristics of the local wind are intrinsic to the parameter $k$ because from it we can obtain wind data, as proposed by (Justus et al., 1976; Manwell et al., 2009) for $1 \leq k<10$ :

Parameter $k$ is determined by below:

$$
k=\left(\frac{\sigma_{V}}{V_{m}}\right)^{-1.086}
$$

where $\sigma_{V}$ is the standard deviation of wind speed data and $V m$ the mean velocity. The ratio $\sigma_{V} / V m$ represents the average turbulence intensity at the site.

Parameter $c$ is determined by:

$$
c=\frac{V_{m}}{\Gamma\left(1+\frac{1}{k}\right)}
$$

where $\Gamma$ is the gamma function.

The gamma function $\Gamma(x)$, for $x>0$, is defined as (Devore, 2006):

$$
\Gamma(x)=\int_{0}^{\infty} e^{-t} t^{x-1} d t
$$

The gamma function satisfies the recursive property in the following way:

$$
\Gamma(x)=(x-1) \cdot \Gamma(x-1)
$$

This notation may be used for all integers, except for the non-positives. However, when $x=n$, where $n$ is a positive integer, the gamma function may be written as a factorial function (Devore, 2006):

$$
\Gamma(n)=(n-1) !
$$

It is observed that $c$ depends on $V m$ and $k$. From $k=2$, when $k$ increases, $c$ tends to decrease as presented in Tab. 1, for a diversity of values of $\mathrm{Vm}$. Thus, with $k$ increasing and $c$, as consequence, decreasing the velocity values tend to concentrate around its mean value.

Table 1. Variation of $k$ and $c$.

\begin{tabular}{|c|c|}
\hline \multicolumn{2}{|c|}{$V m=6 \mathrm{~m} / \mathrm{s}$} \\
\hline$k$ & $c(\mathrm{~m} / \mathrm{s})$ \\
\hline 2 & 6.77 \\
\hline 3 & 6.72 \\
\hline 4 & 6.62 \\
\hline 5 & 6.53 \\
\hline \multicolumn{2}{|c|}{$V m=7 \mathrm{~m} / \mathrm{s}$} \\
\hline$k$ & $c(\mathrm{~m} / \mathrm{s})$ \\
\hline
\end{tabular}

\begin{tabular}{|c|c|}
\hline 2 & 7.90 \\
\hline 3 & 7.84 \\
\hline 4 & 7.72 \\
\hline 5 & 7.62 \\
\hline \multicolumn{2}{|c|}{$V m=8 \mathrm{~m} / \mathrm{s}$} \\
\hline$k$ & $c(\mathrm{~m} / \mathrm{s})$ \\
\hline 2 & 9.03 \\
\hline 3 & 8.96 \\
\hline 4 & 8.83 \\
\hline 5 & 8.71 \\
\hline
\end{tabular}

It is important to notice from Tab. 1 that the higher the mean velocity in the site, the higher the $c$ for the same $k$, as shown in Fig. 5. This means that for a site with a mean velocity of $6 \mathrm{~m} / \mathrm{s}$, for example, values of local velocities tend to be more constant then in a site with mean velocity of $8 \mathrm{~m} / \mathrm{s}$. A high value of $k$ would be a value equal or more than three. The ideal would be a $k \rightarrow \infty$ and a $c \rightarrow 0$. For example, $k=10$ e $c=2$ would produce a "constant" wind power generation. However, this does not happen in reality since a lower $c$ means a low value of local mean wind speed, making the site improper for power generation.

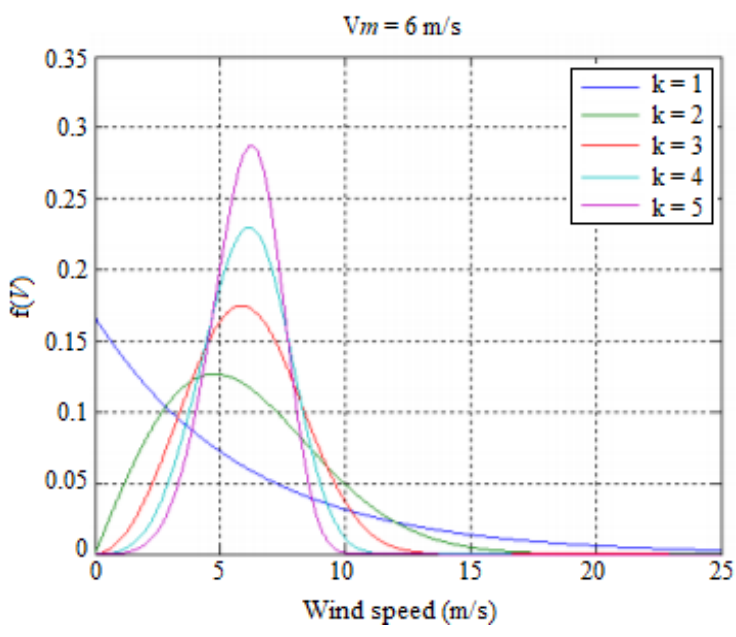

Figure $5 . V m=6 \mathrm{~m} / \mathrm{s}$.

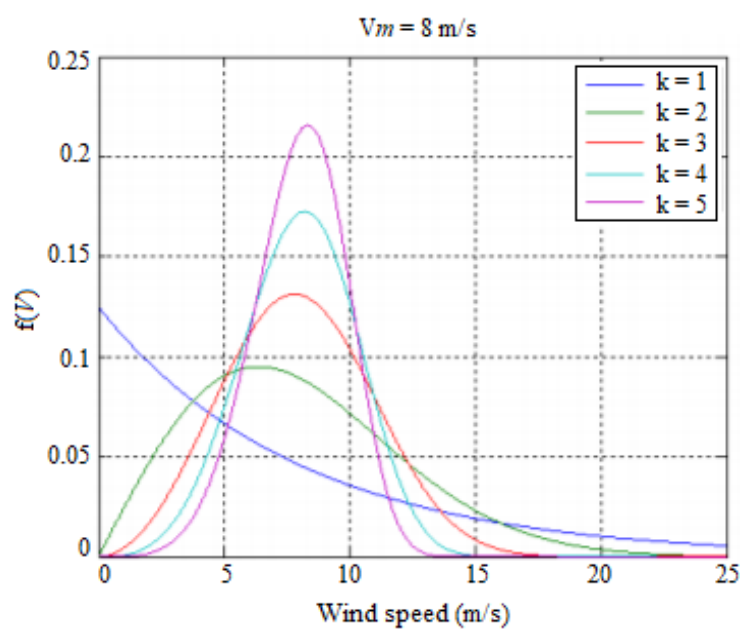

Figure $6 . V m=8 \mathrm{~m} / \mathrm{s}$. 
As can be observed from Figs. 5 and 6, when $k$ $\geq 3$ the wind velocity values are not very much dispersed relative to the mean value. However, when the mean speed goes from 6 to $8 \mathrm{~m} / \mathrm{s}$, there is a higher dispersion for the same $k$, because the parameter $c$ also increased. Still, the values are much more dispersed when $k<3$. The $c$ parameter will adjust the curve so that the PDF will increase or decrease depending on its value (Fig. 5), leaving the analysis of the local wind simply for $k$, i.e., this parameter provides the information related to the wind behavior.

\section{CONCLUSIONS}

The Weibull distribution has been of great importance for wind technology, being the most used probability distribution to represent wind behavior due to its simplicity and versatility.

Analyzing the parameters of the Weibull distribution separately, it can be seen that as the value of $k$ increases, a more consistent wind distribution is obtained, with a higher number of values closer to the mean speed. On the other hand, a higher scale parameter $c$, increases the dispersion of the values around the mean the wind speed. Analyzing both parameters simultaneously, it can be notice that for the same mean wind speed value, an increase of $k$ represents a reduction in the value of the parameter $c$ and the opposite is also true. The ideal, therefore, would be a high value of $k$ and a low value of $c$, but a low value of $c$ also means a low mean wind speed, which is not desirable for wind power generation.

Generally, parameter $c$ will only adjust the scale of the curve, causing the PDF to increase or decrease depending on its value. The analysis of the local wind regime can be done simply by $k$. This work presented a mathematical and physical analysis with didactic purposes, since there is currently no explanatory material in such way.

\section{ACKNOWLEDGEMENTS}

The authors would like to acknowledge the Graduate Program in Mechanical Engineering at the Federal University of Pernambuco (PPGEM/UFPE), CAPES and $\mathrm{CNPq}$ for supporting this work. In addition, we are grateful to the help of all colleagues involved in this work.

\section{REFERENCES}

Arslan, T., Bulut, Y. M., and Yavuz, A. A., 2014, Comparative Study of Numerical Methods for Determining Weibull Parameters for Wind Energy Potential, Renewable and Sustainable Energy Reviews, Vol. 40, pp. 820-825.

Davenport, A. G., 1963, The Relationship of Wind Structure to Wind Loading, National Physical Laboratory.

Devore, J. L., 2006, Probability and Statistics for Engineering and the Science, 6th Edition, Thomson.

Hennessey, J. P., 1977, Some Aspects of Wind Power Statistics, Journal of Applied Meteorology and Climatology, Vol. 16, pp. 119-128.

Johnson, G. L., 2001, Wind Energy Systems, Electronic Edition, Manhattan: Kansas State University.

Jung, C., and Schindler, D., 2017, Global Comparison of the Goodness-of-Fit of Wind Speed Distributions, Energy Conversion and Management, Vol. 133, pp. 216-234.

Justus, C. G., Hargraves, W. R., and Yalcin, A., 1976, Nationwide Assessment of Potential Output from Wind Powered Generators, Journal of Applied Meteorology and Climatology, Vol. 15, pp. 673-678.

Lysen, E. H., 1983, Introduction to Wind Energy, 2nd edition, CWD-Consultancy Services Wind Energy Developing Countries.

Manwell, J. F., McGowan, J. G., and Rogers, A. L., 2009, Wind Energy Explained: Theory, Design and Application, 2nd edition, John Wiley \& Sons.

Mathew, S., 2006, Wind Energy: Fundamentals, Resource Analysis and Economics, Springer.

Morettin, P. A., and Bussab, W. O., 2002, Estatística Básica, 5th edition, Saraiva. (in Portuguese)

Press, W. H., Teukolsky, S. A., Vetterling, W. T., and Flannery, B. P., 2007, Numerical Recipes: The Art of Scientific Computing, 3rd edition, Cambridge University Press.

Rohatgi, J., Araújo, A., and Primo, A. R., 2013, Extreme Wind Speeds and Their Prediction for Wind Turbines, Wind Engineering, Vol. 37, pp. 595-603.

Silva, G., 2003, Características de Vento da Região Nordeste: Análise, Modelagem e Aplicações para Projetos de Centrais Eólicas, Master Thesis, PPGEM-UFPE, Recife, PE. (in Portuguese)

Usta, I., 2016, An Innovative Estimation Method Regarding Weibull Parameters for Wind Energy Applications, Energy, Vol. 106, pp. 301-314.

Weibull, W., 1951, A Statistical Distribution of Wide Applicability, Journal of Applied Mechanics, Vol. 18, pp. 293-297. 